DOI: $10.5604 / 01.3001 .0012 .8035$

\title{
IMPROVEMENT OF METHODS OF MOTION COMPENSATION OF DYNAMIC OBJECTS MOVING IN VIDEO STREAM OF THE VIDEOCONFERENCING SYSTEM
}

\author{
Volodymyr Barannik $^{1}$, Mykola Dvorsky ${ }^{1}$, Valeriy Barannik ${ }^{2}$, Viktoria Himenko ${ }^{2}$, Anton Sorokun ${ }^{2}$ \\ ${ }^{1}$ Ivan Kozhedub Kharkov National University of Air Force, Faculty of Automated Control Systems and Ground Support for Aviation Flights, \\ ${ }^{2}$ Kharkov National University of Radio Electronics
}

\begin{abstract}
Videoconferencing gives us the opportunity to work and communicate in real time, as well as to use collective applications, interactive information exchange. Videoconferencing systems are one of the basic components of the organization of manegment, ensuring, the timeliness and necessary quality management of the implementation of objective control over the solution of the tasks. The quality of the image and the time of transmission of video information is unsatisfactory for the quality control of the troops. Considered ways to increase the efficiency of management and operational activities, due to methods of compensation of motion, using technology to reduce the volume of video data for quality improvement.
\end{abstract}

Keywords: videoconferencing, video stream, coding, motion compensation, troop control

\section{POPRAWA METOD KOMPENSACJI RUCHU PORUSZAJACYCH SIE OBIEKTÓW DYNAMICZNYCH W STREAMIE WIDEO SYSTEMU WIDEOKONFERENCYJNEGO}

Streszczenie. Wideokonferencje daja możliwość pracy i komunikowania się $w$ czasie rzeczywistym, a także korzystania ze zbiorowych aplikacji, interaktywnej wymiany informacji. Systemy wideokonferencyjne sa jednym z podstawowych elementów organizacji zarządzania, zapewniając terminowość $i$ niezbędne zarządzanie jakościa $w$ zakresie realizacji kontroli nad rozwiazaniem zadań. Jakość obrazu $i$ czas transmisji informacji wideo jest niezadowalajacy dla kontroli jakości wojsk. Rozważono sposoby zwiększania efektywności zarzadzania $i$ działań operacyjnych, ze względu na metody kompensacji ruchu, z wykorzystaniem technologii zmniejszajacej ilość danych wideo w celu poprawy jakości.

Słowa kluczowe: wideokonferencje, strumień wideo, kodowanie, kompensacja ruchu, kontrola oddziałów

\section{Introduction}

Due to the rapid development of network and communication technologies, increased productivity of computers, and the need to process more and more information (both local and network and Internet), the role of software and hardware has increased. Remote access, distance education and management, as well as video conferencing facilities are experiencing a period of rapid growth. Bearing your appointment, ease and improve the effectiveness of interaction with both a computer and groups of people with computers integrated into the network.

Video conferencing gives us the opportunity to work and communicate in real time, as well as to use collective applications, interactive information exchange, videoconferences begin to be seen not only as something experimental, but also as a partial solution to the problem of automation of activity and gives a significant advantage over traditional solutions [16].

The basis of video streaming encoding algorithms is the redundancy of information and features of human perception of a visual image [9]. The image changes smoothly, small distortions when the image is restored become incomprehensible [13, 14]. So there were algorithms for encoding a video stream with a loss of quality. Such algorithms allow to efficiently encode the video stream, but do not guarantee accurate information recovery.

\section{Videoconferencing}

Videoconference is an area of informational technology that simultaneously provides two-way transmission, processing, transformation and representation of interactive information at a distance in real time with the help of hardware and software computer facilities.

Interaction in video conferencing mode is also called video conferencing session.

Videoconferencing is a telecommunication technology of interactive interaction between two or more remote subscribers, in which between them it is possible to exchange audio and video information in real time, taking into account the transfer of control data.
Table 1. Characteristics of values of average speed of stream of uncoded video information depending on spatial resolution and frame rate for videoconference complexes in departmental control systems

\begin{tabular}{|c|c|c|c|c|}
\hline $\begin{array}{c}\text { Levels } \\
\text { of video } \\
\text { quality }\end{array}$ & $\begin{array}{c}\text { Number } \\
\text { of rows }\end{array}$ & $\begin{array}{c}\text { Vertical } \\
\text { resolution }\end{array}$ & $\begin{array}{c}\text { Frequency } \\
\text { of frames } \\
\text { per second }\end{array}$ & $\begin{array}{c}\text { Average } \\
\text { speed } \\
\text { (Mbps) }\end{array}$ \\
\hline CIF & $320-352$ & $240-288$ & $24-30$ & 66 \\
\hline SD & 640 & $480-576$ & $24-30$ & 252 \\
\hline ED & 720 & $480-576$ & 50 & 500 \\
\hline HD & 1280 & 720 & 50 & 1105 \\
\hline Full HD & $1280-1920$ & $720-1080$ & $24-30 ; 50$ & $1500 ; 2500$ \\
\hline $\begin{array}{c}\text { Advantage } \\
\text { HD }\end{array}$ & $1920-2048$ & 1080 & $48 ; 60$ & $2548 ; 3180$ \\
\hline
\end{tabular}

The presented assessments are based on the analysis of the main characteristics of telecommunication technologies used in the organization of videoconference in the system of troop control and assessments of the required volumes of video resource videoconference depending on the required spatial resolution of video and frame rates [1,2]. With the growth of the volume of video information and the lack of provision of appropriate data on the productivity of technology for the transmission and processing of video information in the complexes of videoconference, there are conditions for violating the security categories of the video resource of the videoconference - accessibility and integrity.

The high quality of sound and full screen video, the operational exchange of documents and data (allowing video conferencing) gives this tool of distance communication the widest range of practical applications. To date, these systems have already been used in large companies, law firms, medicine and the armed forces.

After telephone conversations, the information received from the interlocutor of the audience, reaches, on average, up to $10 \%$ of the total amount of information.

With telephone conversations with the ability to exchange data, the amount of information collected can be increased to approximately $25 \%$. 
In case when it is possible during the conversation to visually monitor the interlocutor, it is possible to ensure assimilation of information up to $60 \%$. But not only this statistics convinces us that the videoconference allows to provide a connection of a new level.

In practice, video conferencing is an indispensable assistant in the management and interaction of military units that are territorially diverse, advised, experienced in the management of troops, in providing moral and psychological support to troops in the zones of vision of hostilities, in telemedicine, in the transmission of audiovisual transmission from the battlefield. In this case, there is no need to send them to expensive business trips. Cost savings on business trips are not all advantages, the main thing - using video conferencing increases the efficiency of work.

Video conferencing can be arranged on wired and wireless communication channels [7, 20]. Leading channels differ from wireless data rates by cost of construction and ease of implementation.

Recently, Internet access systems based on the use of satellite systems have become widely distributed. Since transmission equipment is expensive, many companies use DirecPC systems. Most often when working with the Internet incoming traffic ("from the Internet") is much higher than the original. DirecPC systems use satellite antennas as receiving devices, but transmit information from users to the Internet via regular terrestrial communication channels. Conventional communications satellites are in stationary orbits at an altitude of approximately 35 kilometers above the Earth. New low-orbit satellites (or low-orbit satellites) operate in orbits close to the earth's surface, allowing them to receive signals even from low-power transmitters. Such satellites consume less power, and their launch and operation cost much less than traditional satellite communications systems.

The use of low-orbital satellites makes it possible to use communication services while in any part of the globe.

Technological implementation options, the telecommunication network usually contains a variety of hardware and software components that need to work together to transmit information. The various components of the network "communicate" with each other, following a series of rules that allows them to work all together. Such a set of rules that governs the process of transferring data between two network points is called a protocol. Each device on the network must correctly understand the protocol of another device.

The effectiveness of videoconference systems in this paper is considered as the efficiency of the transmission of video streams.

\section{Methods motion compensation of dynamic objects moving in video stream}

Methods of compression are divided into two groups: methods for loss of image quality and methods without loss of quality. Lossless image compression is a method where no loss of image quality is achieved compared to the original one. Unsafe image is mathematically identical to its original [18, 19]. Lossless compression typically provides lower compression ratios than compression loss.

Existing compression methods do not ensure the effective operation of objective video control systems [8, 11]. This is manifested in the delayed display of information on the operator's screen, in the low quality of the information received [12].

Motion compensation is one of the main algorithms used in the processing and compression of video data. The algorithm uses the similarity of neighboring frames in a video sequence and finds the motion vectors of individual parts of the image (usually blocks of $16 \times 16$ and $8 \times 8$ ). Use of compensation allows compression to increase the degree of compression by eliminating redundancy in the form of matching parts of frames. It is used not only for compression, but also for filtering video, changing the frame rate.

Motion compensation is one of the most important component part of the MPEG 1 and MPEG 2 standards. The method of compensation motion prediction can significantly reduce the temporal redundancy of video streams. If the next frame contains the shifted parts of the previous frame, then in this case, it is advantageous not to transfer the whole frame, but only information about the movement and changes of the shifted pixel.

The algorithms of compensation of motion can be carried out according to the following criteria:

- the analyzed element - a frame, blocks, or objects [10];

- type of movement - operations of parallel shifts, turns, scaling;

- measure of decision.

There are following methods of motion compensation:

- pixel method;

- object method;

- block matching method.

The pixel method is one of the earliest methods of motion compensation. Compensation is performed separately for each pixel of the frame, which is considered a class of transformations - linear shifts.

The approach is based on the assumption that the brightness can be approximated by a linear function from the point position in the frame. This assumption is valid only for a relatively small neighborhood of this point, which significantly reduces the scope of this method and allows him to correctly evaluate only small shifts. This restriction can be overcome by evaluating not the shear vector itself, but its difference with some prediction vector, which is located closer to the desired vector than zero [17]. In the general case, when the motion can make dozens of pixels, the vector of displacement is searched with the help of an iterative algorithm - at each step there is a refinement of the value found in the previous step. As an initial approximation, we can take the shear vector for the same point found when processing the previous frame. This method has a number of serious shortcomings, as a result of which at present it is purely theoretical interest and is practically not used anywhere. Its main drawbacks are high complexity, low accuracy and a large amount of information.

The object method is a precursor to the method of matching the blocks, where as a compensation element a rectangular block of the frame acts and the compensation is a rectangular block of the frame and linear shifts are considered.

When block approach (Object method) for each block compensation is made regardless of adjacent blocks. Proceeding from the fact that the motion of the scene carries out objects, it is necessary that compensation for all the blocks of the same object gave the same result. This can be done if one or another object of the scene moves to each frame unit. After that you will be able to estimate the total compensation error for all blocks.

The segmentation process can take place regardless of the process of finding the parameters of the movement, either both, and the other can be defined within a single process, which is repeated iteratively. In the first case, the basis for segmentation is usually high-quality information, in the second segmentation is made taking into account the found parameters of motion, which then specify. Sometimes frame segmentation on objects is used after determining the displacement vector for individual blocks in order to correct the found vector field.

Thus, the proposed method is proposed as follows:

1) Accumulate information about the background in a temporary plane (subject to the time frame for the accumulation of information is a sharp change in the background part of the scene) and accumulation of it in the form of a single background for some sequence of personnel. In addition, similar accumulation of information about moving objects of the scene can be similar, taking into account the nature of their movement;

2) Conducting simultaneous construction of a difference image of a scene with a given threshold and segmentation of allocated objects of motion (for segmentation, it is proposed to use information about the eight binding boundary of the pixel of the image). In addition, during the segmentation segment is 
filtered left after a different comparison with the specified threshold noise.

The use of the proposed method will improve the quality of motion compensation by smoothing random emissions into the field of motion vectors inherent in block methods. Accumulation of information in a temporary plane will reduce the noise level of the scene, as well as increase the degree of compression of the video.

The method of matching the blocks, more precisely, the class of methods, is the logical consequence of the pixel method of dynamic objects, eliminates most of its disadvantages, since the unit of compensation in it adopted a rectangular block (usually a square $16 \times 16$ pixels or smaller). The motion is also sought in the class of linear displacements; therefore, this motion describes a two-dimensional bias vector for each block.

The basic assumption of the method - for the time that passes between two consecutive frames, the objects in the scene and their location vary slightly. Then in the vicinity of any point in the frame, this change with a fairly high degree of accuracy can be approximated by parallel transfer of this neighborhood to a certain vector. In fact, the vast majority of ordinary video sequences satisfy this limitation, with the exception of areas of abrupt change in the scene, that is, the nature of the motion of objects can be considered almost everywhere continuous.

Various modifications to this approach differ in how the minimum function of the compensation error is in the whole area. Checking only a few points in the area can localize this minimum. The algorithm by which these points are selected is called a template.

Methods based on templates show a good rate of performance, but often find a local minimum instead of a global one. It is advantageous to note that the search for the vector of motion for each individual block does not depend on the results of the search in adjacent blocks and in the previous frame, which makes the method more effective in a very intense and complex movement $[3,4]$.

After analyzing these methods, their main advantages and disadvantages, which are presented, are revealed.

Pixel method. Disadvantages: high complexity, low accuracy, large amount of information.

Object method. Advantages: high-noise method. Disadvantages: high computational complexity.

Blocks comparison method. Advantages: high accuracy Disadvantages: not a high processing speed

To increase the efficiency of the method of matching the blocks using different templates for finding similar blocks in the next frames.

For optimal work of videoconferencing in the control system and operational communication, the development of a new template - six-point.

The schematic of the six-point search is as follows. First, six blocks are considered. Then, if one of the blocks is the best candidate among others, then the search center shifts there, and the distance between the points shrinks two times $[5,6]$. Such actions are repeated as long as the distance between the blocks becomes equal to one.

$$
K_{j+1}\left(x_{1} ; y_{1}\right)=K_{j}\left(x_{0} ; y_{0}\right),
$$

where $K_{j+l}$ is an interpolated frame; $\left(x_{0} ; y_{0}\right)$ is coordinates of the center of the current frame; $\left(x_{1} ; y_{1}\right)$ is center coordinates of the interpolated frame.

Formula (1) represents the coordinate of the center of two neighboring frames.

The calculation of the upper left point:

$$
\mathrm{K}_{j+1}\left(-4 x_{1} ;\left(\mathrm{y}_{1}+4\right)\right)=\frac{\left[K_{j}\left(x_{0} ; y_{0}\right)+K_{j}\left(-4 x_{0} ;\left(y_{0}+4\right)\right)\right]}{2},
$$

Top right point calculation:

$$
\mathrm{K}_{j+1}\left(4 x_{1} ;\left(\mathrm{y}_{1}+4\right)\right)=\frac{\left[K_{j}\left(x_{0} ; y_{0}\right)+K_{j}\left(4 x_{0} ;\left(y_{0}+4\right)\right)\right]}{2},
$$

Left point calculation:

$$
\mathrm{K}_{j+1}\left(-6 x_{1} ; \mathrm{y}_{1}\right)=\frac{\left[K_{j}\left(x_{0} ; y_{0}\right)+K_{j}\left(-6 x_{0} ; y_{0}\right)\right]}{2},
$$

Right-pointcalculation:

$$
\mathrm{K}_{j+1}\left(6 x_{1} ; \mathrm{y}_{1}\right)=\frac{\left[K_{j}\left(x_{0} ; y_{0}\right)+K_{j}\left(6 x_{0} ; y_{0}\right)\right]}{2}
$$

Lower left point calculation:

$$
\mathrm{K}_{j+1}\left(-4 x_{i} ;\left(\mathrm{y}_{1}-4\right)\right)=\frac{\left[K_{j}\left(x_{0} ; y_{0}\right)+K_{j}\left(-4 x_{0} ;\left(y_{0}-4\right)\right)\right]}{2},
$$

Lower right point calculation:

$$
\mathrm{K}_{j+1}\left(4 x_{1} ;\left(\mathrm{y}_{1}-4\right)\right)=\frac{\left[K_{j}\left(x_{0} ; y_{0}\right)+K_{j}\left(4 x_{0} ;\left(y_{0}-4\right)\right)\right]}{2},
$$

According to the formulas, the following cohorts of each of the six points are calculated. These calculations are repeated until the distance between the blocks becomes equal to one.

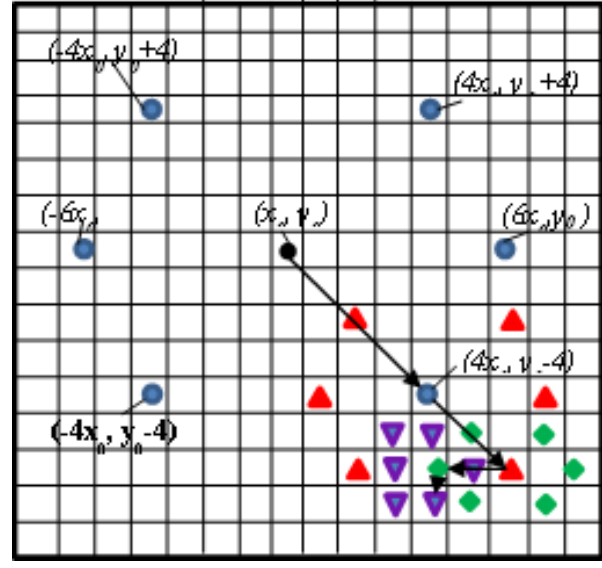

Fig. 1. Possible ways of convergence of the six-point algorithm of search

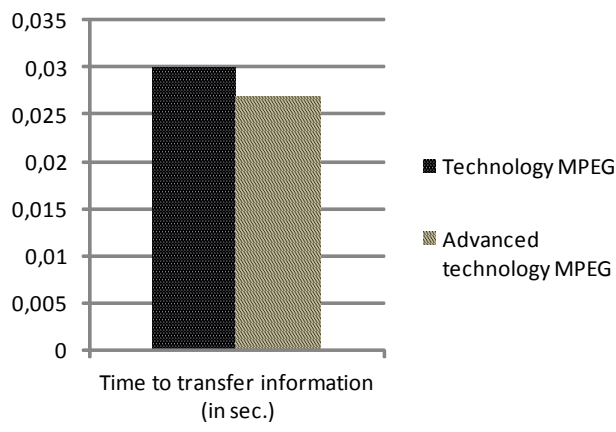

Fig. 2. Comparative characteristics of information transmission time (in sec.) of MPEG technology and after its improvement

After comparative characteristics of the time of information transmission of standardized MPEG technology before and after the improvement of the method of matching the blocks, the effectiveness of the application of the template can be seen.

\section{Conclusions}

Considered methods of motion compensation in a video data stream. Having analyzed the methods of encoding the stamping of a video data flow, it is interesting to study the possibility of further increasing the coefficient of coding for methods of series lengths due to the additional use of methods of compensation of motion.

As a consequence, it is proposed to improve the method of matching the blocks of motion compensation by simplifying the use of templates.

Video stream speed estimation is performed depending on the quality of video data required, from spatial resolution and frame rate. With the tendency of growth of volumes of video information and not providing the corresponding data volumes of the productivity of technologies of transmission and processing of video information in complexes videoconference - it is necessary to improve the coding methods. In future, it is necessary to improve the methods of motion compensation for other standardized technologies of encoding video information. 


\section{References}

[1] Baccouch H., Ageneau P. L., Tizon N., Boukhatem N.: Prioritized network coding scheme for multi-layer video streaming. Proc. 14th IEEE Annual Consumer Communications \& Networking Conference (CCNC), Las Vegas, 2017, 802-809.

[2] Bai X., Wang J.: Towards temporally-coherent video matting. Proceedings of the 5th international conference on Computer vision/computer graphics collaboration techniques - MIRAGE'11, 2011, 63-74

[3] Barannik V., Krasnorutsky A., Larin V., Hahanova A., Shulgin S.: Mode of syntactic representation of aerophoto images segments. Proc of. XVI-th Intern. conf: Modern Problems of Radio Engineering, Telecommunications and Computer Science, 2018, 974-977 [doi: 10.1109/TCSET.2018.8336356].

[4] Barannik V., Ryabukha Yu., Barannik D., Podlesny S.: The Information Integrity Enhance in Telecommunication Systems with the Binomia Coding. 4th International Scientific-Practical Conference, 2017, 547-550 [doi: 10.1109/INFOCOMMST.2017.8246459].

[5] Barannik V., Ryabukha Yu., Tverdokhlib V., Dodukh A., Suprun O., Tarasenko D.: Integration the non-equilibrium position encoding into the compression technology of the transformed images. East-West Design \& Test Symposium (EWDTS), 2017, 1-4 [doi: 10.1109/EWDTS.2017.8110030].

[6] Barannik V. V., Ryabukha Yu. N., Tverdokhleb V. V., Baranmk D. V.: Methodological basis for constructing a method for compressing of transformants bit representation, based on non-equilibrium positional encoding. 2nd IEEE International Conference on Advanced Information and Communication Technologies - AICT, 2017, 188-192 [doi: 10.1109/AIACT.2017.8020096]

[7] Christophe E., Lager D., Mailhes C.: Quality criteria benchmark for hiperspectral imagery. IEEE Transactions on Geoscience and Remote Sensing 43(9), 2005, 2103-2114

[8] Ding Z., Chen H., Gua Y., Peng Q.: GPU accelerated interactive space-time video matting. Computer Graphics International, 2010, 163-168.

[9] Gonzales R. C., Woods R. E.: Digital image processing. Prentice Hall, New Jersey 2002

[10] Grundmann M., Kwatra V., Han M., Essa I. Efficient hierarchical graph based video segmentation. IEEE CVPR, 2010, 85-91.

[11] Lee S. Y. Yoon J. C.: Temporally coherent video matting. Graphical Models 72 2010, 25-33.

[12] Lezama J., Alahari K., Sivic J., Laptev I.: Track to the future: Spatio-temporal video segmentation with long-range motion cues. Proceedings of the IEEE Conference on Computer Vision and Pattern Recognition, 2011, 256-289.

[13] Miano J.: Compressed image file formats: JPEG, PNG, GIF, XBM, BMP Addison-Wesley Professional, New York 1999

[14] Miano J.: Formats and image compression algorithms in action [Text]. Triumph, Kiev 2013.

[15] Pratt W. K., Chen W. H., Welch L. R.: Slant transform image coding. Proc Computer Processing in communications. Polytechnic Press, New York 1969.

[16] Recommendations of the International Telecommunication Union ITU-T G.1010 "End-User multimedia QoS categories".

[17] Stankiewicz O., Wegner K., Karwowski D., Stankowski J., Klimaszewski K. Grajek T.: Encoding mode selection in HEVC with the use of noise reduction. International Conference on Systems, Signals and Image Processing (IWSSIP), 2017, 1-6.

[18] Wang S., Zhang X., Liu X., Zhang J. , Ma S., Gao W.: Utility-Driven Adaptive Preprocessing for Screen Content Video Compression. IEEE Transactions on Multimedia 19(3), 660-667.

[19] Zhang Y., Negahdaripour S., Li Q.: Error-resilient coding for underwater video transmission. OCEANS 2016 MTS/IEEE Monterey 2016, 1-7.

[20] Zheng B., Gao S.: A soft-output error control method for wireless video transmission. 8th IEEE International Conference on Communication Software and Networks (ICCSN), 2016, 561-564.
Mykola Dvorsky

e-mail:dmv06@i.ua

A cadet of Ivan Kozhedub Kharkov Nationa University of Air Force. Soldier Dvorsky Mykola Vitaliiovich is a winner of the All-Ukrainian Students Competition of science-based works in the field of the telecommunications.

ORCID ID: 0000-0003-0497-5676

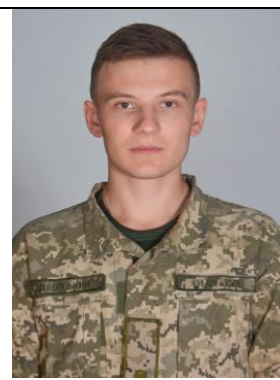

D.Sc. Volodymyr Barannik
e-mail: vvbar.off@ gmail.com

Doctor of technical sciences, professor.Head of the department of combat use and operation of the ACS since 2012. Scientific interests: information security. Publications: more than 550 scientific publications, including monographs, textbooks, teaching aids, scientific articles and patents for inventions.

ORCID ID: 0000-0002-2848-4524

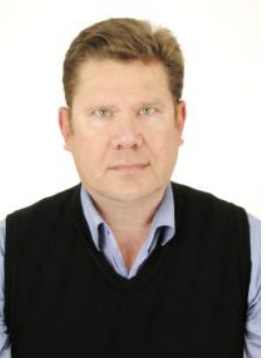

\section{Valeriy Barannik}

e-mail: valera462000@gmail.com

Student of the Kharkov national university of Radio Electronics. Scientific interests: systems, technologies of transformation, encoding, defence and information transfer, semantic processing of images.

ORCID ID: 0000-0003-3516-5553

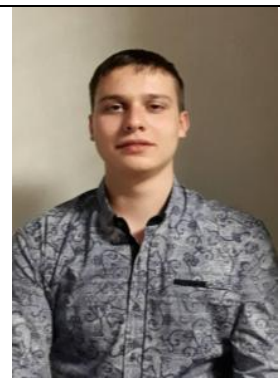

\section{Viktoria Himenko}

e-mail: vika.iv55@gmail.com

Position: graduate student of Kharkov National University of Radio Electronics. Research interests: information security, information coding. Publications: more than 10 scientific publications.

ORCID ID: 0000-0002-1337-2404

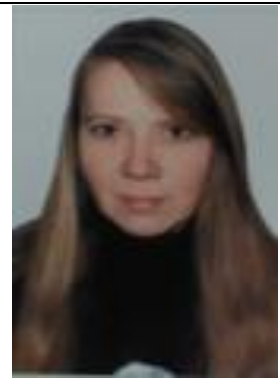

\section{Anton Sorokun}

e-mail: anton.sorokun@gmail.com

Ministry of Education and Science of Ukraine Kharkov National University of Radio Electronics

ORCID ID: 0000-0001-8469-641X

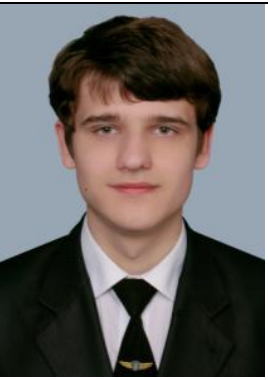

otrzymano/received: 1.10 .2018 